\title{
Personalien
}

Todesfälle / Décès / Decessi

Hugo Josef Battaglia (1959), † 15.8.2020,

Facharzt für Chirurgie, 6353 Weggis

François Villoz (1949), † 30.9.2020,

Spécialiste en psychiatrie et psychothérapie, 1009 Pully

Hans Ulrich Rothen (1951), † 7.10.2020,

Facharzt für Anästhesiologie und Facharzt

für Intensivmedizin, 3013 Bern

Céline Sèvegrand Beuret (1965), † 7.10.2020,

Médecin praticien, 1845 Noville

\section{Praxiseröffnungen /}

Nouveaux cabinets médicaux /

Nuovi studi medici

GE

Eleni Kalogeropoulou, Spécialiste en psychiatrie et psychothérapie, place des Eaux-Vives 3, 1207 Genève
VD

Hélène de Rocquigny du Fayel,

Spécialiste en psychiatrie et psychothérapie, rue Saint-Martin 2, 1003 Lausanne

ZG

Christopher Soll, Facharzt für Chirurgie, Dorfplatz 1, 6330 Cham

ZH

Judit Apli, Fachärztin für Ophthalmologie, Gerbestrasse 4, 8820 Wädenswil

Ärztegesellschaft des Kantons Bern Ärztlicher Bezirksverein Bern Regio Zur Aufnahme als ordentliches Mitglied hat sich angemeldet:

Christoph Hauser, Facharzt für Allgemeine Innere Medizin und Facharzt für Infektiologie, FMH, Bremgartenstrasse 119, 3012 Bern
Einsprachen gegen dieses Vorhaben müssen innerhalb 14 Tagen seit der Veröffentlichung schriftlich und begründet bei den Co-Präsidenten des Ärztlichen Bezirksvereins Bern Regio eingereicht werden. Nach Ablauf der Frist entscheidet der Vorstand über die Aufnahme der Gesuche und über die allfälligen Einsprachen.

\section{Ärztegesellschaft Thurgau}

Zum Eintritt in die Ärztegesellschaft Thurgau haben sich gemeldet:

Martin Blay, Löwenstrasse 16, 8280 Kreuzlingen, Facharzt für Chirurgie und Facharzt für Orthopädische Chirurgie und Traumatologie des Bewegungsapparates, FMH

Vinzenz Mühlstein, Sonnenstrasse 13c, 8280 Kreuzlingen, Facharzt für Psychiatrie und Psychotherapie, FMH

\section{Aktuelle Themen auf unserer Website} www.saez.ch $\rightarrow$ tour d'horizon

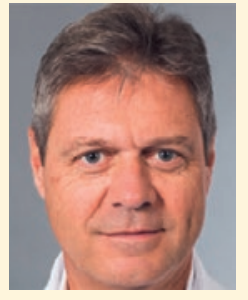

Interview mit Prof. Alain Gervaix, Universitätsspital Genf

\section{Das Stethoskop, das Covid-19 erkennen kann}

Prof. Alain Gervaix entwickelt ein Stethoskop, das dank künstlicher Intelligenz den Ton von Covid-19 erkennen kann.

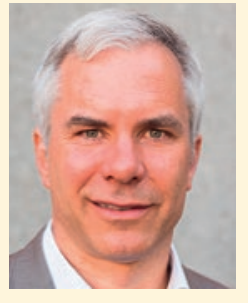

Interview mit Martin Ackermann, Leiter der «Swiss National COVID-19 Science Task Force»

\section{«Nehmen Sie selbst das Virus ernst und werden Sie so zum Vorbild»}

Martin Ackermann, der neue Leiter der Science Task Force, über die aktuellen Herausforderungen rund um Covid-19. 